\title{
Comparisons of azo dye adsorptions onto activated carbon and silicon carbide nanoparticles loaded on activated carbon
}

\author{
E. Ghasemian ${ }^{1} \cdot$ Z. Palizban $^{1}$
}

Received: 9 February 2015/Revised: 16 July 2015/Accepted: 5 August 2015/Published online: 18 August 2015

(C) Islamic Azad University (IAU) 2015

\begin{abstract}
This paper presents a comparative study of the surface chemistry, texture, and adsorption properties of activated carbon and silicon carbide nanoparticles loaded on activated carbon. Activated carbon has been prepared from the pulp of oak cups using a chemical activation method, with silicon carbide nanoparticles used to modify the surface of activated carbon. Scanning electron microscopy, Fourier transform infrared spectroscopy, $\mathrm{N}_{2}$ adsorption-desorption isotherms, and points of zero charge determination are the methods that have been employed to determine the physicochemical properties of raw material, activated carbon, and silicon carbide nanoparticles loaded on activated carbon, respectively. Results demonstrated that the activated carbon is composed mainly of micropores, with a Brunauer-EmmettTeller surface area of $1253.92\left(\mathrm{~m}^{2} / \mathrm{g}\right)$, and that the attachment of silicon carbide nanoparticles changed the surface properties of activated carbon. The adsorption equilibrium of two azo dyes on activated carbon and silicon carbide nanoparticles loaded on activated carbon was investigated using the Langmuir, Freundlich, and Temkin isotherms. Experimental data were fitted to conventional kinetic models, including the pseudo-first-order, second-order, Elovich, and intraparticle diffusion models. For all adsorbents, the removal process follows the pseudo-second-order kinetic model. Equilibrium
\end{abstract}

Electronic supplementary material The online version of this article (doi:10.1007/s13762-015-0875-1) contains supplementary material, which is available to authorized users.

E. Ghasemian

e.ghasemian@Ilam.ac.ir

1 Faculty of Science, Ilam University, P.O. Box 69315516, Ilam, Iran adsorption parameters reveal that a higher adsorption capacity was found for silicon carbide nanoparticles loaded on activated carbon. These features indicate that silicon carbide nanoparticle-activated carbon is a promising and new adsorbent for the removal of acidic dyes during wastewater treatment.z

Keywords Activation - Congo red - Isotherm - Methyl orange $\cdot$ Modification $\cdot$ Points of zero charge $\cdot$ Surface area

\section{Introduction}

The textile industry is an intensive industry with high water consumption and discharge (Wu et al. 2013). One of the major pollutants found in water resources discharged around textile industries is dye, and more than one million tons of dyes are produced annually worldwide (Subramonian and Wu 2014). Among the dyes, azo dyes are one of the most important compounds that are widely used in the textiles, leather, cosmetics, and chemical industries. These dyes are chemical compounds bearing the functional group $\mathrm{R}-\mathrm{N}=\mathrm{N}-\mathrm{R}^{\prime}$, in which $\mathrm{R}$ and $\mathrm{R}$ can be either aryl or alkyl. The chemical and photochemical stability of these compounds poses acute challenges to ecological systems; for this reason, numerous studies on chemical precipitation, their adsorption on activated carbon and catalytic oxidation, and on the overall electrochemical process have been performed for the purpose of removing azo dyes from aqueous environments (Ghazi Mokri et al. 2015; Mezohegyi et al. 2012).

One of the most powerful and convenient adsorption processes is based on the application of activated carbon or modified activated carbon (Neill et al. 1999). The activated carbons (or ACs) are adsorbents containing a high surface 
area and an appreciable amount of active sites available for adsorption-that is, sites with sufficient affinity to retain certain pollutants. Commercial production of activated carbon in recent times has been performed by the physical or chemical activation of a wide variety of materials, including pulp from coconut shells (Gueu et al. 2007), Ferula orientalis (Aysu and Kucuk 2015), phoenix leaves (Wang 2015), cotton stalks (El-Hendawy et al. 2008), rice husk (Manoj Kumar Reddy et al. 2015), fir wood (Wu et al. 2005a, b), pistachio nut shells (Wu et al. 2005a, b), olive stones (Ubago-Perez et al. 2006), flamboyant pods or Delonix regia (Vargas et al. 2010), and macadamia nut shells (Poinern et al. 2011).

In this work, experimental studies to produce activated carbon from the pulp of oak cups by chemical activation are presented. During chemical activation, carbonization and activation are accomplished with phosphoric acid to promote the cleavage reaction. Surface and textural characterization of prepared activated carbon using Fourier transform infrared spectroscopy (FT-IR), scanning electron microscopy (SEM), and $\mathrm{pH}$ at the point of zero charge $\left(\mathrm{pH}_{\mathrm{PZC}}\right)$ was carried out. The specific surface area and pore size distribution of the activated carbons were characterized by $\mathrm{N}_{2}$ adsorption-desorption isotherms at $77 \mathrm{~K}$ in a gas adsorption instrument.

This work also focused on the modification of the surface of activated carbon using silicon carbide nanoparticles (SiCNPs), which has potential interest for many applications such as dyes and organic pollutant removal (Zolfaghari et al. 2013; Ghaedi et al. 2013a, b; Ameta et al. 2006). SiCNPs are some of the most useful materials due to their significant hardness, considerable strength, and high oxidation resistance (Hwang and Nishihara 1998; Lavrenko et al. 1999; Pezzotti and Sakai 1994; Pham-Huu et al. 1998). These materials are widely applied in the ceramic industry for use at high temperatures and as additives for increasing the strength or thermal properties of composite materials.

Surface modification of activated carbon using SiCNPs has not been reported in the literature. The FT-IR analysis and SEM images indicate that the nanoparticles were evenly developed on the entire activated carbon surface; $\mathrm{pH}_{\mathrm{PZC}}$ showed the predominance of basic groups on the SiCNP-AC surface. Finally, the kinetics, thermodynamics, and isotherms for the removal of azo dyes using this novel adsorbent were investigated.

This research was conducted in Department of Chemistry, Faculty of Science, Ilam University, Ilam, Iran, from September 2014 to January 2015.

\section{Materials and methods}

\section{Materials}

The raw material was first washed with double-distilled water and then oven-dried at $100{ }^{\circ} \mathrm{C}$ for $48 \mathrm{~h}$. The dried pulp from the oak cups was crushed in a laboratory mill and sieved until it attained a small particle size. Due to its low ash content and high amount of volatile matter, oak cup pulp is a good feedstock for activated carbon production.

All chemicals used in this study, such as $\mathrm{H}_{3} \mathrm{PO}_{4}(99 \%)$, $\mathrm{HCl}$ (99\%), methyl orange (MO), and Congo red (CR), were of the highest purity available and purchased from Merck (Darmstadt, Germany). Stock solutions of methyl orange and Congo red $\left(1000 \mathrm{mg} \mathrm{L}^{-1}\right)$ were prepared and suitably diluted to the required initial concentration. The SiCNPs were supplied by a nanomaterial manufacturing company (US Research Nanomaterials, Inc., Houston, Texas, USA) and produced using the plasma-enhanced chemical vapor deposition (PECVD) method. The results demonstrated that the SiCNPs have a BET surface area of $177 \mathrm{~m}^{2} / \mathrm{g}$.

\section{Methods}

The $\mathrm{pH}$ measurements were taken using $\mathrm{pH} / \mathrm{Ion}$ meter model-682 (Metrohm, Switzerland), and absorption studies were carried out using the Jusco (Japan) UV-Visible spectrophotometer (model V-570). The shape and surface morphology of the samples were investigated using a scanning electron microscope (SEM; VEGA model, TESCAN Company, Brno, Czech Republic) with an acceleration voltage of $20 \mathrm{kV}$. The FT-IR spectra of some of the activated carbons were obtained using a spectrophotometer (Bruker-Germany VERTEX70; Ettlingen, Germany). The BET surface area measurements were obtained from nitrogen adsorption isotherms using a Micrometrics Surface Area Analyzer (Chem BET-3000, Quantachrome C; Quantachrome Instruments, Boynton Beach, Florida, USA).

A Boehm method was used for the calculation of the number of acidic and basic groups on the particles' surfaces. This method is based on acid-base titration with $\mathrm{NaOH}, \mathrm{Na}_{2} \mathrm{CO}_{3}, \mathrm{NaHCO}_{3}$, and $\mathrm{HCl}$. The following procedure was used: $0.5 \mathrm{~g}$ of the powder and $25 \mathrm{~mL}$ of $0.05 \mathrm{M}$ $\mathrm{NaOH}, \mathrm{Na}_{2} \mathrm{CO}_{3}, \mathrm{NaHCO}_{3}$, or $\mathrm{HCl}$ solution were agitated for $3 \mathrm{~h}$. In the next step, $5 \mathrm{~mL}$ of each filtrate was pipetted, and the excess of base or acid was titrated with $0.05 \mathrm{M} \mathrm{HCl}$ or $\mathrm{NaOH}$, respectively (Lopez-Ramon et al. 1999). 


\section{Preparation of activated carbon}

Dried raw materials were mixed with $\mathrm{H}_{3} \mathrm{PO}_{4}$ solution at $\mathrm{H}_{3} \mathrm{PO}_{4} / \mathrm{C}$ mass ratios of $1-1$, and the mixture was dried at $105^{\circ} \mathrm{C}$ for $12 \mathrm{~h}$. The obtained material was pyrolyzed in a stainless steel reactor at a rate of $7\left({ }^{\circ} \mathrm{C} / \mathrm{min}\right)$ to $600{ }^{\circ} \mathrm{C}$ for $2 \mathrm{~h}$ and maintained for 100 min under $\mathrm{N}_{2}$ flow protection. After cooling, the activated carbon was boiled with $200 \mathrm{~mL}$ of $10 \% \mathrm{HCl}$ solution for $60 \mathrm{~min}$, separated by filtration, and washed with water to eliminate the inorganic species. For the last step, the activated carbon was dried in an oven at $110{ }^{\circ} \mathrm{C}$ for $24 \mathrm{~h}$ (Timura et al. 2010).

\section{Synthesis of activated carbons loaded with SiCNP (SiCNPs-AC)}

SiCNP loading on activated carbon was carried out by mixing activated carbon powder with nanoparticle deionized water solution in a large and open Erlenmeyer flask under magnetic stirring for $10 \mathrm{~h}$ until the $\mathrm{SiC}$ nanoparticles were deposited onto surface of activated carbon. The activated carbon (supported with SiCNPs) was then filtered and extensively washed with double-distilled water.

\section{Batch adsorption experiments}

The stock solution of dye was prepared in a flask with an adsorbent concentration of $0.5 \mathrm{~g} / 150 \mathrm{ml}$; all of the adsorption experiments were carried out at $175 \mathrm{rpm}$ in an orbital shaker. The dye concentration was measured within a time range of 5-70 min until equilibrium was reached. The experiments with the adsorption isotherms were conducted in a solution at $\mathrm{pH} 5.0$ with initial dye concentrations ranging from 5 to $100 \mathrm{mg} / \mathrm{L}$. Investigation of the $\mathrm{pH}$ effect was performed within an initial concentration range of $81-100 \mathrm{mg} / \mathrm{L}$ for the dyes. The $\mathrm{pH}$ of the solution ranged from 2.0 to 12.0 .

The following equation was used to calculate the percentage removal for the dye:

$\%$ dye removal $=\frac{C_{0}-C_{t}}{C_{0}} \times 100$

where $C_{0}(\mathrm{mg} / \mathrm{L})$ and $\mathrm{C}_{t}(\mathrm{mg} / \mathrm{L})$ are the initial and final concentrations of dye, respectively. The maximum adsorbed amount at equilibrium, $\left(q_{\mathrm{e}}(\mathrm{mg} / \mathrm{g})\right)$, was calculated according to Eq. (2):

$q_{e}=\left(C_{0}-C_{e}\right) \frac{V}{W}$

where $C_{e}\left(\mathrm{mg} \mathrm{L}^{-1}\right)$ represents the equilibrium liquid-phase concentrations of dye, $V(\mathrm{~L})$ is the volume of the solution, and $W(\mathrm{~g})$ is the adsorbent mass.

\section{Results and discussion}

\section{Characterization of activated carbon}

Comparisons of the SEM images of the raw material and the activated carbon surface (shown in Fig. 1a, b) confirmed that the surface of activated carbon is porous and relatively smooth. As expected, the degree of porosity and the internal surface area of activated carbon changed after
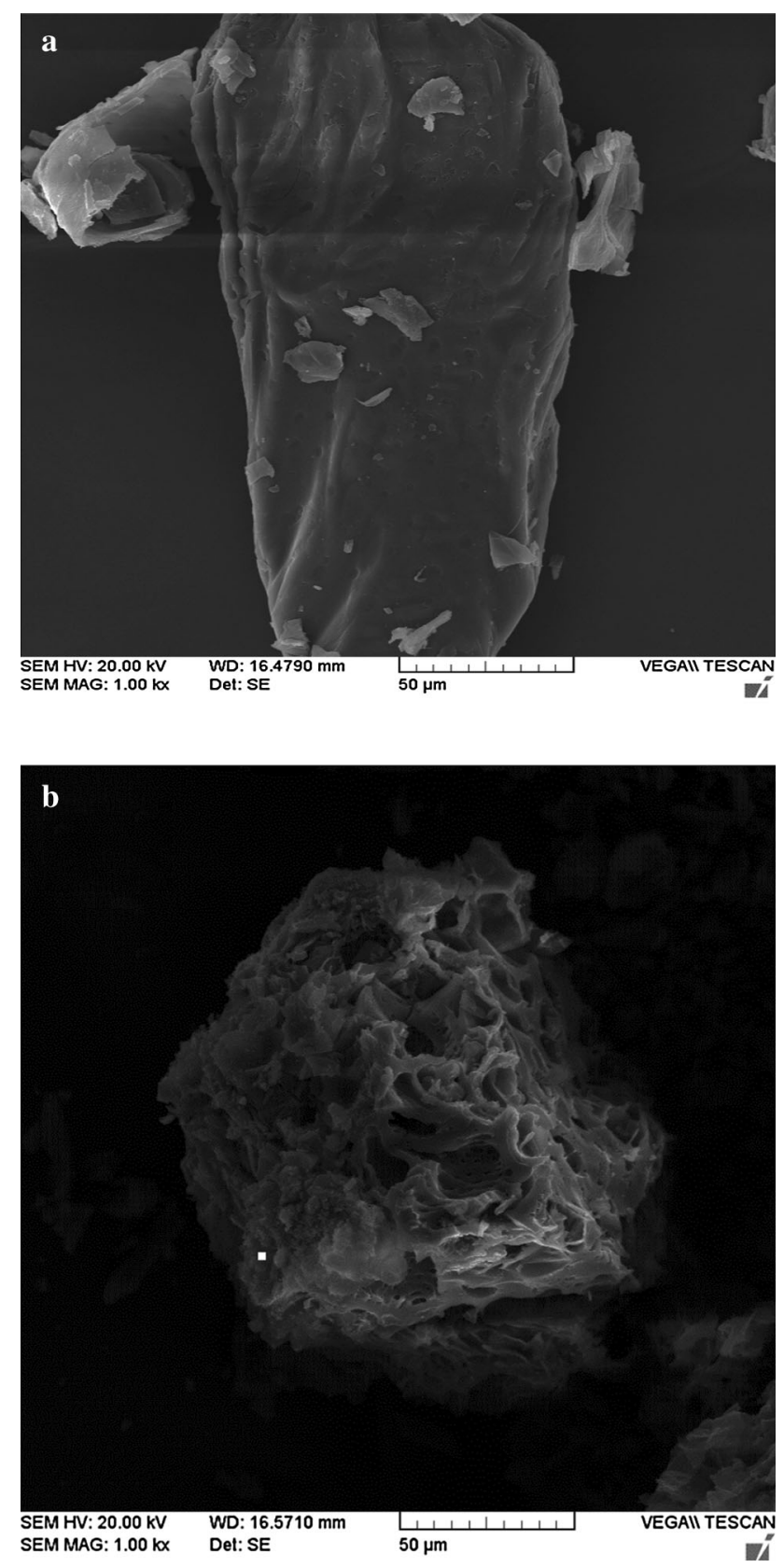

Fig. 1 SEM images of a raw material and $\mathbf{b}$ activated carbon prepared using oak acorn cup 
the activation process. During activation, the internal surface becomes more highly developed and extended by controlled oxidation of carbon atoms. Most of the pores were enlarged to a size within the range of $10-20 \mu \mathrm{m}$.

As illustrated in Fig. 2, the $\mathrm{N}_{2}$ adsorption isotherm at $77 \mathrm{~K}$ for the activated carbon and SiCNP-AC sample is clearly of type IV. According to the IUPAC classification, the type IV isotherm is characteristic of materials with a texture of micro- and mesopores. Specific surface area was calculated using the Brunauer-Emmett-Teller (BET) method, taking $1253.92\left(\mathrm{~m}^{2} / \mathrm{g}\right)$ for the cross-sectional area of the nitrogen-adsorbed molecules. Different surface area values for lignocellulosic materials have been reported in the literature. These differences are due to the differences in the type of starting materials and the activation method. To provide one example, the activated carbons obtained from wood (Hu et al. 2009), and Ferula orientalis (Aysu and Kucuk 2015) using zinc chloride had surface areas of 1718,1450 , and $1476\left(\mathrm{~m}^{2} / \mathrm{g}\right)$, respectively, while the surface areas obtained from activated carbon based on olive kernels (Zabaniotou et al. 2008), bamboo-derived granular activated carbon (Denga et al. 2015), and using KOH had
Fig. $2 \mathrm{~N}_{2}$ adsorption and desorption isotherms at $77 \mathrm{~K}$ (a) and pore size distribution of $\mathrm{AC}(\mathbf{b})$
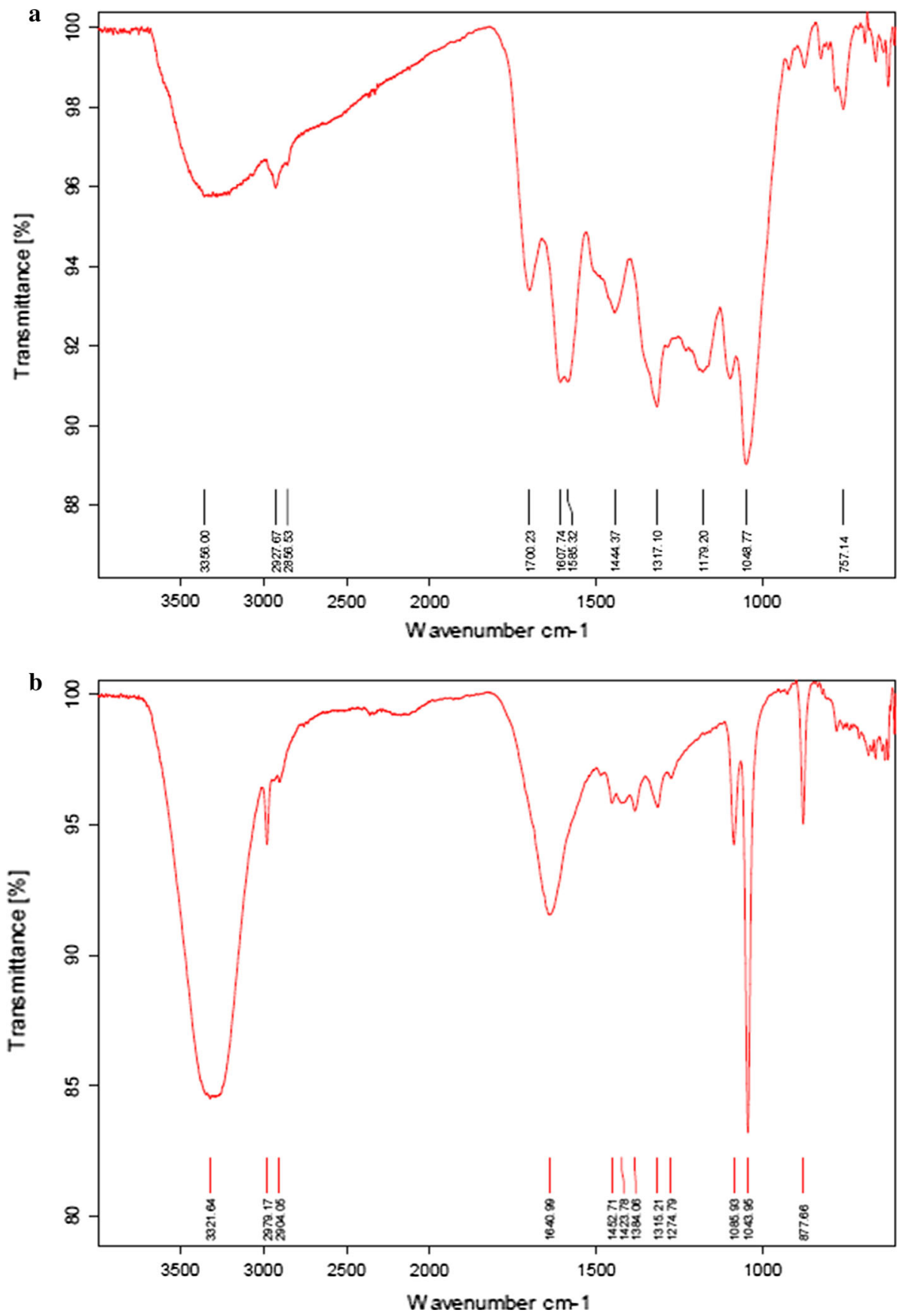
respective surface areas of 3049 and $3000\left(\mathrm{~m}^{2} / \mathrm{g}\right)$. The adsorptive properties of the surfaces of nanoscale AC particles have been compared with those of the SiCNP-AC adsorbent and are given in Table 1. From Table (S1), it can be seen that activated carbon and SiCNP-AC have respective BET surface areas of 1253.92 and $1092.445\left(\mathrm{~m}^{2} /\right.$ g). The activated carbon supported by SiCNP-AC showed a low surface area as well as a lower area composed of micropores compared to activated carbon. The $\mathrm{N}_{2}$ adsorption-desorption of these materials is shown in Fig. 2. Higher $\mathrm{N}_{2}$ adsorption levels occur when carbon is activated at a low pressure $\left(P / P_{0}<0.5\right)$.

FT-IR spectrum analysis was used to investigate variations in the functional groups of the adsorbents. FT-IR spectra for the raw material and activated carbon are presented in Fig. 3. As can be observed, the activated carbon spectrum exhibited fewer absorption bands than did the raw material spectrum, mainly between 1700 and $1000 \mathrm{~cm}^{-1}$, indicating that some functional groups present in the raw material disappeared after the carbonization and activation steps. FT-IR investigation also revealed the presence of various functional group and reactive atoms, including the carboxylic acid and hydroxide group the with proton exchange ability. The FT-IR spectrum of activated carbon in Fig. 2 showed adsorption peaks around $3000-3500 \mathrm{~cm}^{-1}$, which is indicative of the existence of bonded hydroxyl groups. The peak observed at $2979 \mathrm{~cm}^{-1}$ can be assigned to the $\mathrm{C}-\mathrm{H}$ group. The peak observed at $1640 \mathrm{~cm}^{-1}$ is due to $\mathrm{C}=\mathrm{N}$. The peak around $1200-1400 \mathrm{~cm}^{-1}$ is due to the $\mathrm{C}-\mathrm{C}$. The peak around $1043 \mathrm{~cm}^{-1}$ can be assigned to the $\mathrm{C}-\mathrm{O}$ group. The adsorption band at $877 \mathrm{~cm}^{-1}$ is also ascribed to the symmetric bending of the $\mathrm{C}-\mathrm{H}$ group.

The $\mathrm{pH}_{\mathrm{PZC}}$ of activated carbons was obtained using the pH drift method (Ghaedi et al. 2014) by adding activated

Table 1 Isotherm constant and correlation coefficients calculated for Congo red and methyl orange adsorption onto SiC-AC and $\mathrm{AC}$

\begin{tabular}{llccccc}
\hline Isotherm & Parameters & \multicolumn{2}{c}{ Methyl orange } & & \multicolumn{2}{c}{ Congo red } \\
\cline { 3 - 4 } \cline { 6 - 7 } \cline { 7 - 7 } Langmuir & $Q_{m}(\mathrm{mg} / \mathrm{g})$ & 40.160 & 27.32 & & 78.740 & 4.88 \\
& $K_{a}\left(\mathrm{~L} \mathrm{mg}^{-1}\right)$ & 0.033 & 0.58 & & 0.012 & 0.202 \\
& $R^{2}$ & 0.995 & 0.998 & & 0.980 & 0.992 \\
Freundlich & $1 / n$ & 0.190 & 1.066 & & 0.779 & 0.09 \\
& $K_{f}\left(\mathrm{~L} \mathrm{mg}^{-1}\right)$ & 6.210 & 0.617 & & 1.416 & 9.58 \\
& $R^{2}$ & 0.977 & 0.976 & & 0.9999 & 0.946 \\
Tempkin & $B_{I}$ & 14.580 & 13.73 & & 29.960 & 1.34 \\
& $K_{T}\left(\mathrm{~L} \mathrm{mg}^{-1}\right)$ & 1.314 & 0.2231 & 2.150 & 1.031 \\
& $R^{2}$ & 0.975 & 0.9611 & 0.982 & 0.985 \\
\hline
\end{tabular}

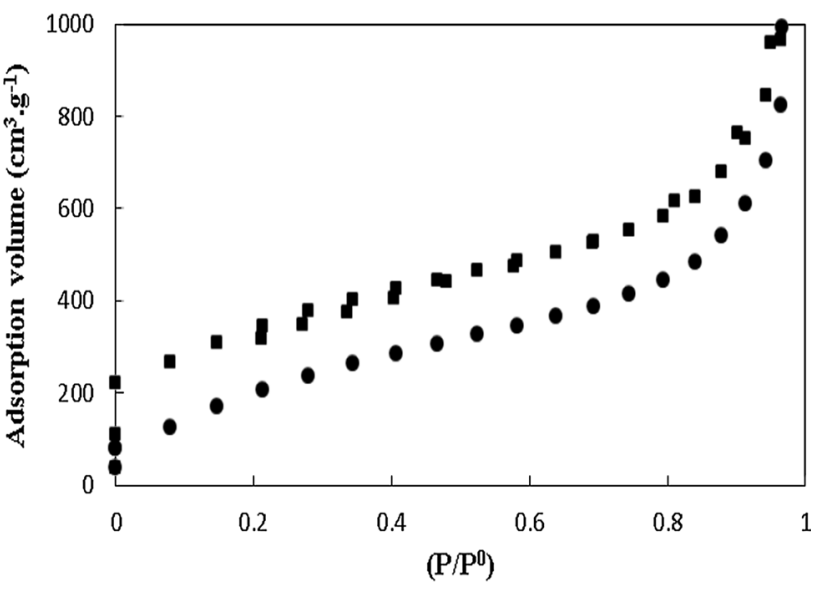

Fig. 3 FT-IR spectra of raw material $(a)$ and prepared activated carbon $(b)$ from oak acorn cup

carbon in the $\mathrm{NaCl}$ solutions. The $\mathrm{pH}_{\mathrm{PZC}}$ value $(=8.3)$ shows chemical activation of the sample increasing, primarily with respect to the concentration of the basic group (especially ketons, ether, and pyrones). This value complies with the results obtained by Boehm titration, which showed the predominance of basic groups on the surface of activated carbon.

Phosphoric acid is the most widely used chemical agents for dehydration of lignocellulosic materials at lower temperatures. $\mathrm{H}_{3} \mathrm{PO}_{4}$ has two important functions-it accelerates the cleavage of bonds between biopolymers (principally cellulose and lignin), followed by formation of phosphate linkages between the fragments in the biopolymer pyrolytic (Li et al. 2008).

Figure 4 shows an SEM image of the SiCNPs deposited onto the surface of the activated carbon. The SEM image indicates that the sizes of the SiCNPs are within a range from 30 to $60 \mathrm{~nm}$, with the nanoparticles evenly deposited on the entire surface of activated carbon. The functional groups of the SiCNP-AC were investigated using FT-IR spectra (Fig. 5), displaying a number of absorption peaks around $3400 \mathrm{~cm}^{-1}$ that correspond to the existence of hydroxyl groups. The peak observed at $1600 \mathrm{~cm}^{-1}$ is attributed to $\mathrm{C}=\mathrm{N}$, and the peak at $1200 \mathrm{~cm}^{-1}$ attributed to the $\mathrm{C}-\mathrm{C}$ bond. The peak at about $800-900 \mathrm{~cm}^{-1}$ is due to the $\mathrm{C}-\mathrm{H}$ bond. Attenuation in the intensity of the bands is evidence of a change in the functionality of the activated carbon. Also the peak emerged at $800-900 \mathrm{~cm}^{-1}$ which is corresponded to the $\mathrm{Si}-\mathrm{C}$ bond and presented peak at $1000-1200 \mathrm{~cm}^{-1}$ belongs to small fraction of (Si-O) bonds.

In addition, the change in $\mathrm{pH}_{\mathrm{PZC}}$ values from 8.3 for activated carbon to 7.4 for SiCNP-AC reveals the decrease 


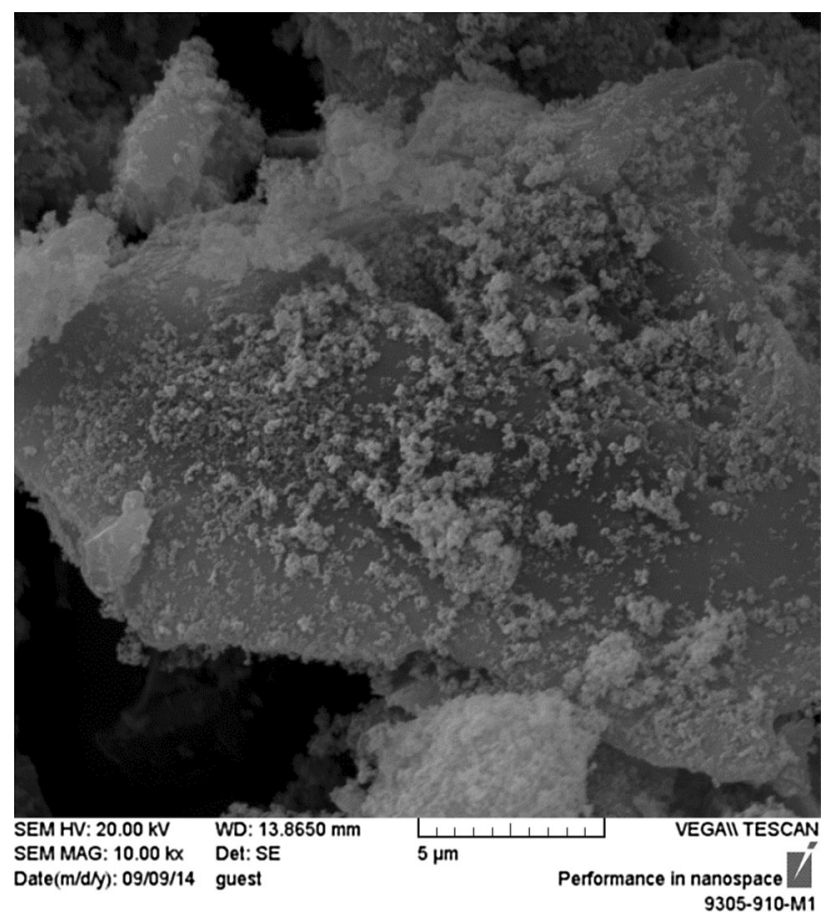

Fig. 4 SEM image of the SiC nanoparticles deposited on activated carbon

in basic groups on the surface of activated carbon due to electrostatic interactions between positive and negative groups of SiCNPs and activated carbon.

Many recent publications describe the modifying of surface SiCNPs (Kim and Kim 2014; Rudnik 2013; Pourreza and Naghdi 2014). The results of the Boehm titration of silicon carbide particles in the present work and literature indicate that the specific surface charge of the $\mathrm{SiC}$ powder was positive.

\section{Effect of pH}

The initial $\mathrm{pH}$ has a distinct role in the chemistry of dye, the surface charge on the adsorbent, electrostatic interaction, hydrogen bonding formation, electron donor-acceptor, and $\pi-\pi$ dispersion interactions in solution (Vargas et al. 2011).

The effect of initial $\mathrm{pH}$ on the adsorption of methyl orange and Congo red onto SiCNP-AC and activated carbon was studied under acidity and alkaline conditions; the results are given in Fig. 6. The typical plots (as presented in Fig. 6) confirm that adsorption of Congo red is strongly influenced by $\mathrm{pH}$, which is explained based on the point of zero charge (PZC). It was clearly observed that the removal percentage decreased as the $\mathrm{pH}$ value of solution came close to alkaline conditions.

This behavior is explained based on the PZC. At $\mathrm{pH}<\mathrm{PZC}$, the carbon surface may be positively charged due to protonation of the carboxyl and other functional groups. Under these conditions, the attraction between dye anions and the adsorbent surface, and the subsequent high adsorption, may be expected (Manoj Kumar Reddy et al. 2015). In the present study, the $\mathrm{pH}$ values for the zero charge for activated carbon and SiCNP-AC were found to be approximately $\mathrm{pH}=8.3$ and $\mathrm{pH}=7.4$, respectively. Therefore, at low $\mathrm{pH}(\mathrm{pH}<8)$, the adsorbent surface has a positive charge and adsorbs the Congo red and methyl orange dyes via electrostatic attraction.

\section{Effect of contact time}

Equilibrium time is one of the most important parameters in the evaluation of adsorption efficiency. Rapid uptake and
Fig. 5 FT-IR spectra of SiC nanoparticles deposited on activated carbon

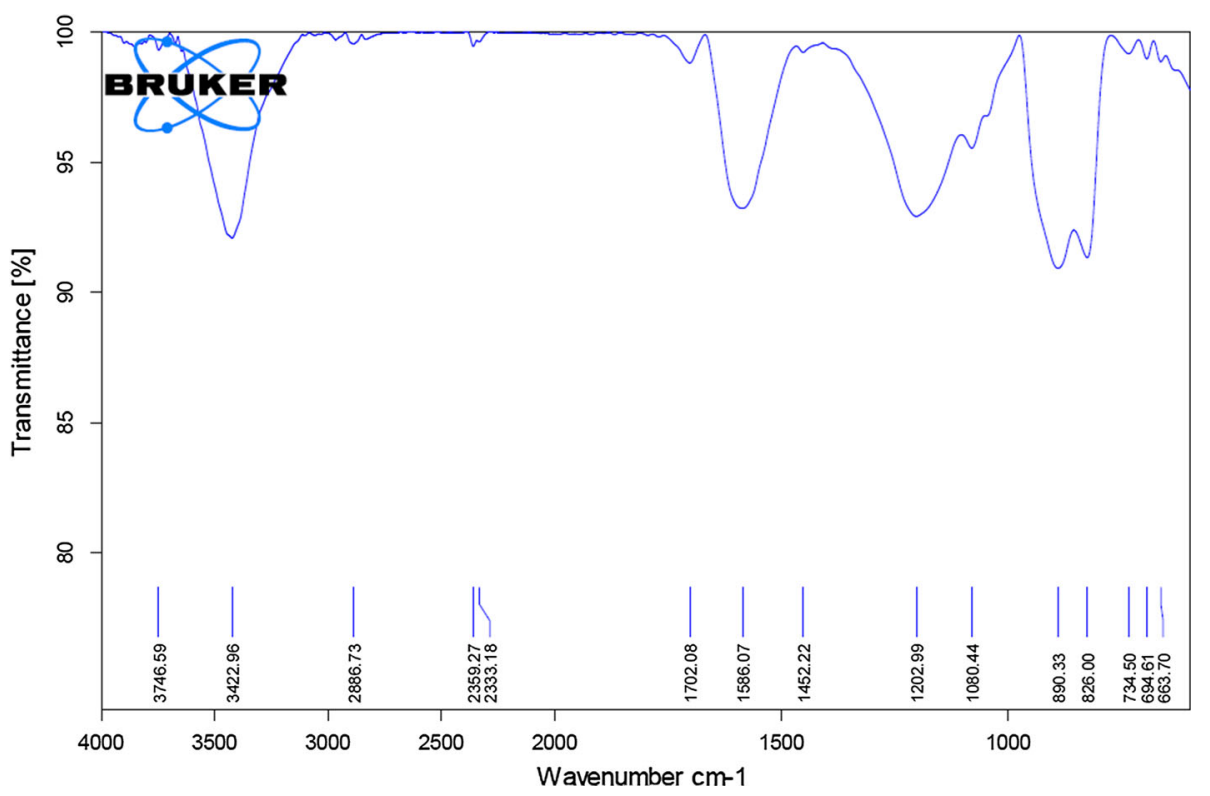




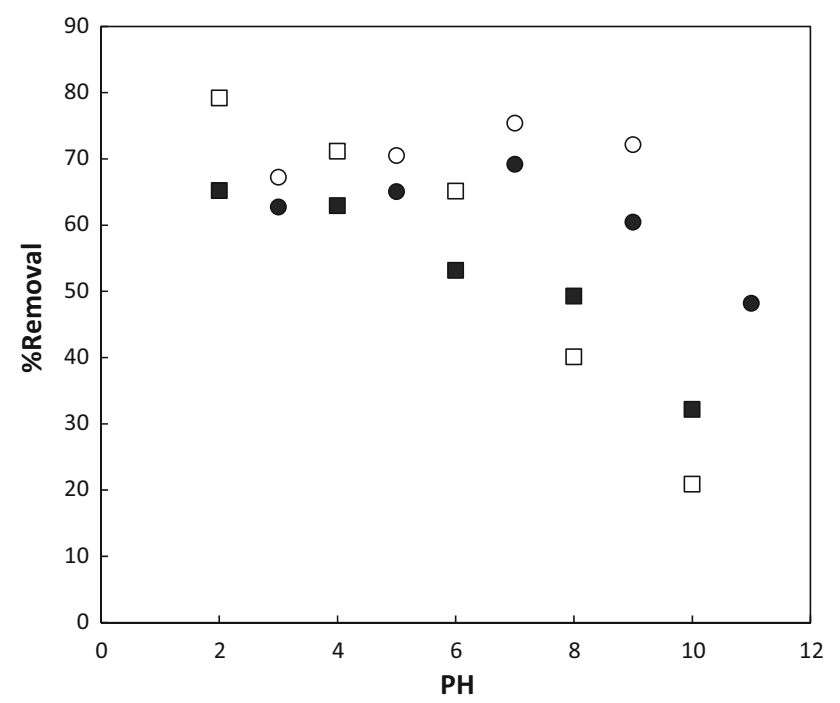

Fig. 6 Effect of $\mathrm{pH}$ on the removal of Congo red onto (open square) $\mathrm{AC}$; (filled square) SiC-NP-AC and methyl orange onto (open circle) AC; (filled circle) SiC-NP-AC

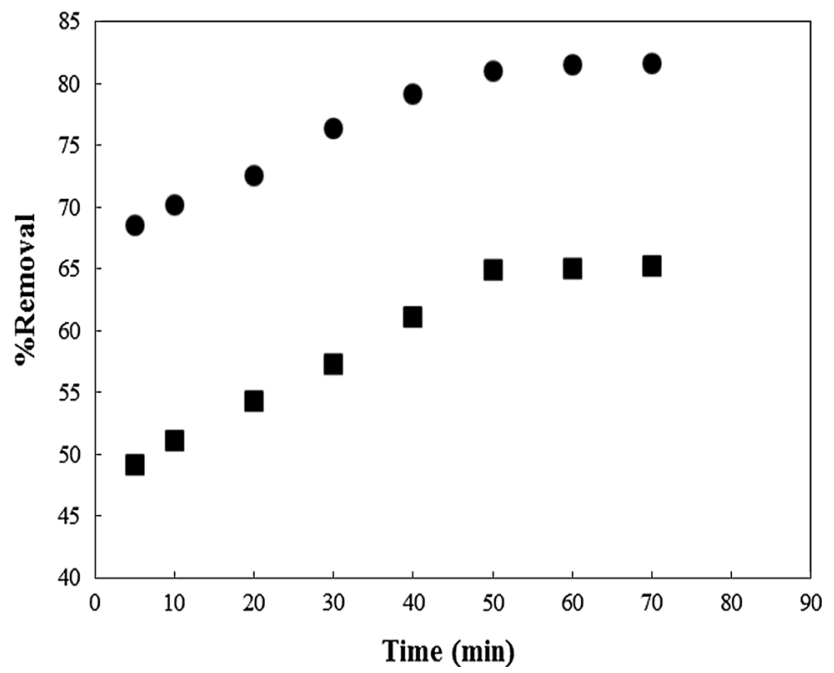

Fig. 7 Effect of contact time on the removal of (filled square) Congo red; (filled circle) methyl orange on SiC-NP-AC

quick establishment of equilibrium time imply the efficiency of a particular adsorbent in wastewater treatment. The typical kinetic curves showing the adsorption of dyes onto activated carbon and SiCNP-AC are shown in Fig. 7 typically. The extent of adsorption is rapid during the initial stages, becoming slow during the later stages until saturation is achieved. This shows that equilibrium can be assumed to be achieved after 50 min-equilibrium being basically due to the saturation of the active site, at which time further adsorption cannot take place (Chatterjee et al. 2007; Rengaraj et al. 2004).

\section{Effect of adsorbent dose}

The adsorbent dose is an important parameter in adsorption studies because it determines the capacity of adsorbent for a given initial concentration of dye solution. The effect of the adsorbent dose on the removal of the methyl orange and Congo red was studied by varying the adsorbent amount between 0.025 and $0.5 \mathrm{~g}$ for SiCNP-AC and activated carbon at fixed times, $\mathrm{pH}$ values, temperatures, and dye concentrations, respectively (this is shown in the supplementary figure, "Fig. s1").

It was observed that the removal percentage increased rapidly at first with the increase in adsorbent dose till $0.15 \mathrm{~g}$, and after the critical dose, the removal percentage almost reached a constant value. This can be attributed to increase the adsorbent surface area and availability of more adsorption sites with the increasing dosage of the adsorbent, while the adsorption density of dye decreased when the adsorbent dosage was increased (Alishavandi et al. 2013; Zakaria et al. 2009; Kannan and Sundaram 2001).

\section{Effect of temperature}

Various textile dye effluents are produced at relatively high temperatures. Therefore, to discern the endothermic or exothermic nature of the adsorption process, the removal of dyes was studied by varying the temperature between 293.15 and 333.15 K. The data presented in Fig.s2 (in supplementary files) showed that adsorption of methyl orange and Congo red by the SiCNP-AC and by activated carbon decreased with increase in temperature, which is typical for exothermic adsorption. The decrease in adsorption with increasing temperatures suggests weak adsorption interactions between adsorbent surfaces and the dye molecules.

\section{Effect of initial dye concentration and adsorption isotherms}

It is worth while to compare the effect of the initial dye concentration on the adsorption process onto activated carbon and SiCNP-AC. The results related to the effect of the initial methyl orange and Congo red concentrations on the adsorption rate are given in Fig.s3 (refer to the supplementary files). The amount of adsorption increased for dyes onto both activated carbon and SiCNP-AC when the initial concentration was changed from 0.02 to 20 (mg/L). The single, smooth, and continuous curve of these compounds can be ascribed to the $S_{2}$ type, according to the Giles classification scheme (Giles and Smith 1973). This type of curve is typical for microporous sorbents and was observed with monolayer sorption of microporous activated carbon (Strachowski and Bystrzejewski 2015). 
Activated carbon is an excellent adsorbent for most organic compounds due to the special surface area and the various surface functional groups (containing oxygen, nitrogen, and other heteroatoms) identified on activated carbon. Heteroatoms are incorporated into the network.

These results can be attributed to the fact that loading of SiCNPs onto the AC surface leads to the extension of the adsorption mechanism to other pathways, such as soft-soft and electrostatic interactions. The loading of SiCNPs on activated carbon simultaneously leads to a decrease in surface area and an increase in reactive sites for dye adsorption.

Adsorption isotherms describe the equilibrium of the adsorption of a material on a surface (more generally, at the boundary of a surface) at a constant temperature. It represents the amount of material bound at the surface (the sorbate) as a function of the material present in the gas phase and/or in the solution. In the present work, the Langmuir (1916), Freundlich (1906), and Temkin isotherms (Temkin and Pyzhev 1940) were used to analyze the experimental equilibrium data.

The Langmuir isotherm was developed by Irving Langmuir in 1916 to describe the pressure dependence of the surface coverage and gas pressure at a fixed temperature. The linear form of this model is presented as follows:

$\frac{C_{e}}{q_{e}}=\frac{1}{K_{L} Q_{m}}+\frac{C_{e}}{Q_{m}}$

where $K_{L}$ is the Langmuir adsorption constant $(\mathrm{L} / \mathrm{mg})$, and $Q_{m}$ is the theoretical maximum adsorption capacity $(\mathrm{mg} / \mathrm{g})$. These parameters were obtained from a plot of $\left(C_{e} / q_{e}\right)$ versus $C_{e}$ and are listed in Table 1 . A correlation coefficient $\left(\mathrm{R}^{2}\right)$ of 0.99 (Table 1 ) indicates that this isotherm is suitable for adsorption prediction.

The values for the adsorption capacity and the correlation coefficient show the SiCNP-AC had a relatively good adsorption capacity of $78.74 \mathrm{mg} / \mathrm{g}$ for methyl orange and $40.16 \mathrm{mg} / \mathrm{g}$ for Congo red as compared to some data obtained from the literature $(76.92 \mathrm{mg} / \mathrm{g}$ for Pd-NP-AC and $66.666 \mathrm{mg} / \mathrm{g}$ for Ag-NP-AC) (Ghaedi et al. 2014). Generally, adsorption capacity is affected by the surface area of activated carbon, the pore size of carbon, the solubility of solute in aqueous solution, the $\mathrm{pH}$, and temperature. Substances that are slightly soluble in water are more easily removed from water (i.e., adsorbed) than substances with high solubility. Also, nonpolar substances will be more easily removed than polar substances since the latter have a greater affinity for water.

Table 1 provides a comparison of the maximum adsorption capacities $Q_{m}$ for the adsorbents studied in the present work. The maximum adsorption capacities of AC for methyl orange and Congo red, respectively, are 27.32 and $4.88 \mathrm{mg} / \mathrm{g}$. These values are low when compared to the maximum adsorption capacity of SiCNP-AC. That the order $Q_{m}$ of adsorbents relates to the order of the respective surface charges rather than to the surface molar area of similar findings has been revealed in the literature for the adsorption of cations onto palladium, silver, and zinc oxide nanoparticles loaded on activated carbon. According to the authors, the complexing of dyes with metals present in the adsorbents is primarily responsible for their high $Q_{m}$ (Ghaedi et al. 2013a, b). The K parameter evaluated from the Langmuir equation is an equilibrium constant that visualizes the affinity of the solute toward the adsorbent surface.

The Freundlich isotherm based on the well-known assumption for dye adsorption on heterogeneous surfaces can be expressed in the linear form as follows:

$\log q_{e}=\log K_{f}+\frac{1}{n} \log C_{e}$

where $n$ is the Freundlich constant related to adsorption intensity (which indicates how favorable the process is) and $K_{f}$ is the Freundlich constant related to the relative adsorption capacity of the adsorbent when the adsorption process is physical $(n>1)$, chemical $(n<1)$, or linear $(n=1)$. The ratio $1 / \mathrm{n}$ provides information related to the surface heterogeneity. Therefore, the material surface becomes more heterogeneous the closer to zero the $1 / \mathrm{n}$ value approaches. In the current study, the $1 / \mathrm{n}$ value was 0.09 for activated carbon, indicating that activated carbon has a high degree of heterogeneity.

In a similar manner, the Temkin and Pyzhev isotherm, in terms of a dimensionless binding energy $\left(K_{T}\right)$, may be presented as follows

$q_{e}=B_{1} \ln K_{T}+B_{1} \ln C_{e}$

This isotherm takes into account the indirect adsorbateadsorbate interactions on adsorption isotherms. Temkin noted experimentally that, with adsorption, the temperature would more often decrease than increase with increasing coverage. In Eq. (5) above, $K_{T}$ is the binding energy of adsorbent and adsorbate, $B_{1}(=R T / b)$ is the heat of adsorption, $T$ is the absolute temperature in Kelvin, and $R$ is the universal gas constant $(8.314 \mathrm{~J} / \mathrm{K} \mathrm{mol})$. Values of $B_{1}$ and $K_{T}$ were calculated from the plot of $q_{e}$ against $\ln C_{e}$ (see Table 1). In exothermic and endothermic adsorption reactions, the value of $B_{1}$ is higher and lower than unity, respectively. The reported value of $B_{1}$ in Table 1 indicates that the adsorption reaction of dyes onto activated carbon and SiCNP-AC occurs exothermically in the concentration range studied. This fact suggests that there is an electrostatic interaction, and the heterogeneity of pores on activated carbon and the SiCNP-AC surface plays a significant role in the adsorption of dyes.

By comparing the experimental results with equilibrium isotherm equations, it was found that Langmuir, 
Freundlich, and Temkin isotherms are all well fitted with the experimental data. However, the Langmuir isotherm achieved the best fit.

\section{Adsorption kinetics}

Adsorption kinetics govern the solute uptake rate, measure the adsorption efficiency of the adsorbent, and determine its applicability for explaining the experimental data. Firstly, the adsorption rate of the sorbents was analyzed using Lagergren's first-order rate equation (Tutem et al. 1998; Lu et al. 2006) in linear form as follows:

$\log \left(q_{e}-q_{t}\right)=\log \left(q_{e}\right)-\frac{k_{1}}{2.303 t}$

where $q_{e}$ and $q_{t}$ are adsorption capacity at equilibrium and at time $t$, respectively; and $k_{1}$ is the rate constant of pseudofirst-order adsorption $\left(\mathrm{min}^{-1}\right)$. Values of $k_{1}$ and $q_{e}$ can be determined from the slope and intercept of the plot of log $\left(q_{e-} q_{t}\right)$ versus $t$, respectively. The data in Table 2 show that the pseudo-first-order adsorption rates were not suitable to describe the experimental data, considering the range of values for $R^{2}(0.87-0.89)$ and the fact that the greatest gap appeared between the experimental and theoretical $q_{e}$ values.

The pseudo-second-order model (Kannan and Sundaram 2001) with well-known Eq. (7) was tested to analyze and evaluate the efficiency of experimental data.

$\frac{t}{q_{t}}=\frac{1}{k_{2} q_{e}^{2}}+\frac{1}{q_{e}(t)}$ where $k_{2}$ is the equilibrium rate constant of pseudo-secondorder adsorption ( $\mathrm{g} / \mathrm{mg} \mathrm{min})$. In the pseudo-second-order model, the rate-limiting step is the surface adsorption that involves chemisorption, where the removal from the solution is due to physicochemical interactions between the two phases.

The experimental kinetic data were adjusted according to the indicated model (see Fig. s4 in supplementary materials). The results of $R^{2}, k_{2}$, and $q_{e}$ in Table 2 showed that the second-order equation model provided the best correlation with experimental results. This fact indicates that the sorption of dyes on all adsorbents follows the pseudo-second-order kinetic model.

The Elovich equation was developed to describe adsorption capacity and is generally expressed as:

$q_{t}=\frac{1}{\beta} \ln (\alpha \beta)+\frac{1}{\beta} \ln (t)$

where $q_{t}$ is the amount of adsorbed dye by adsorbent at a time $t, \alpha$ is the initial dye adsorption rate $[\mathrm{mg} /(\mathrm{g} \mathrm{min})]$, and $\beta$ is the desorption constant $(\mathrm{g} / \mathrm{mg})$ during any one experiment. The general explanations for this form of kinetic equation involve variations in the energy of chemisorption, in which the active sites are heterogeneous in the adsorbent. This supports that the heterogeneous sorption mechanism is likely responsible for uptake of the dye. The Elovich model basically supports chemisorption; the Elovich plots of $q_{\mathrm{t}}$ versus $\ln (t)$ yield a linear relationship. The Elovich equation data obtained in this study for methylene orange and Congo red adsorption with AC and SiCNP-AC

Table 2 Adsorption kinetic parameters at initial dye concentration $(20 \mathrm{mg} / \mathrm{L})$ onto SiC-NP-AC and AC

\begin{tabular}{|c|c|c|c|c|c|c|}
\hline \multirow[t]{2}{*}{ Model } & \multirow[t]{2}{*}{ Parameters } & & \multicolumn{2}{|c|}{ Congo red } & \multicolumn{2}{|c|}{ Methyl orange } \\
\hline & & & $\mathrm{SiC}-\mathrm{AC}$ & $\mathrm{AC}$ & $\mathrm{SiC}-\mathrm{AC}$ & $\mathrm{AC}$ \\
\hline \multirow[t]{3}{*}{ First-order kinetic } & $\begin{array}{r}K_{1} \times 10^{-3} \\
\left(\mathrm{~L} \min ^{-1}\right)\end{array}$ & $\begin{array}{l}\text { Rate constant of pseudo-first-order adsorption } \\
\left(\mathrm{L} \min ^{-1}\right)\end{array}$ & 0.069 & 0.104 & 0.059 & 0.137 \\
\hline & $q_{\mathrm{e}}(\mathrm{cal})$. & Equilibrium capacity (mg/g) & 2.75 & 8.7 & 1.15 & 9.54 \\
\hline & $R^{2}$ & Correlation coefficient & 0.93 & 0.9527 & 0.93 & 0.996 \\
\hline \multirow[t]{3}{*}{$\begin{array}{l}\text { Second-order } \\
\text { kinetic }\end{array}$} & $\begin{array}{r}\mathrm{K}_{2} \times 10^{-3} \\
\left(\mathrm{~L} \min ^{-1}\right)\end{array}$ & $\begin{array}{l}\text { Second-order rate constant of adsorption } \\
{[\mathrm{g} /(\mathrm{mg} . \mathrm{min})]}\end{array}$ & 0.043 & 0.018 & 0.027 & 0.06 \\
\hline & $q_{\mathrm{e}}$ (cal.) & Equilibrium capacity (mg/g) & 9.32 & 5.43 & 18.45 & 35.84 \\
\hline & $R^{2}$ & Correlation coefficient & 0.999 & 0.999 & 0.999 & 0.999 \\
\hline \multirow[t]{3}{*}{$\begin{array}{l}\text { Intraparticle } \\
\text { diffusion }\end{array}$} & $K_{\mathrm{dif}}\left(\mathrm{L} \min ^{-1}\right)$ & $\begin{array}{l}\text { Rate constant of intraparticle diffusion } \\
\left(\mathrm{mg} /\left(\mathrm{g} \mathrm{min}{ }^{1 / 2}\right)\right.\end{array}$ & 0.302 & 0.661 & 0.662 & 2.14 \\
\hline & $C$ & Intercept of intraparticle diffusion & 6.82 & 5.98 & 13.29 & 25.46 \\
\hline & $R^{2}$ & Correlation coefficient & 0.98 & 0.9132 & 0.96 & 0.988 \\
\hline \multirow[t]{3}{*}{ Elovich } & $\beta$ & Desorption constant (g/mg) & 1.3745 & 0.23 & 0.7313 & 0.53 \\
\hline & $\alpha$ & Initial adsorption rate $[\mathrm{mg} /(\mathrm{g} \min )]$ & 2.87 & 4.3 & 2.84 & 2.32 \\
\hline & $R^{2}$ & Correlation coefficient & 0.9628 & 0.9321 & 0.92 & 0.9655 \\
\hline$q_{\mathrm{e}}(\mathrm{EXP})$. & & $\begin{array}{l}\text { Experimental data of the equilibrium capacity } \\
(\mathrm{mg} / \mathrm{g})\end{array}$ & 7.15 & 4.88 & 17.8 & 34.76 \\
\hline
\end{tabular}


are summarized in Table 2. The correlation coefficient $\left(R^{2}\right)$ shows the lack of success for the Elovich model.

The last alternative method used in this study for kinetic evaluation is intraparticle diffusion (Rengaraj et al. 2004). The intraparticle diffusion model describes adsorption processes, for which the rate of adsorption depends on the speed at which adsorbate diffuses toward adsorbent (i.e., the process is diffusion controlled), as depicted by Eq. (9) below:

$q_{t}=K_{\mathrm{dif}} t^{1 / 2}+C$

The adsorption data for $q_{t}$ versus $t^{1 / 2}$ for the reactive dyes are shown in two stages (Fig. 7). The first, straight portion depicts macropore diffusion; the second represents micropore diffusion.

The values of $K_{\text {dif }}$ and $C$ were calculated from the slopes of $q_{\mathrm{t}}$ versus $t^{1 / 2}$ and are reported in Table 2. Intraparticle diffusion is the sole rate-limiting step, at the point when the plot of $q_{\mathrm{t}}$ versus $t^{1 / 2}$ passes through the origin, and the value of $C$ (in this case) is equal to zero (shown in Fig. s5 in supplementary materials). This phenomenon shows that the intraparticle diffusion model may be the controlling factor in determining the kinetics of the adsorption of Congo red on the adsorbent (Alishavandi et al. 2013). The distance of $R^{2}$ values (Table 2) from unity for adsorption of dyes on SiCNP-AC and AC indicates the non-applicability of this model that rejects the rate-limiting step in the intraparticle diffusion process. As already mentioned, the adsorption mechanism for any dye removal by an adsorption process may be assumed to involve the following four steps: (1) bulk diffusion; (2) film diffusion; (3) pore diffusion or intraparticle diffusion; (4) adsorption of dye on the sorbent surface (Chen et al. 2010; Khaled et al. 2009). Previous studies showed that such plots may present a multi-linearity, indicating the occurrence of two or more steps. The first, sharper portion is the external surface adsorption or instantaneous adsorption stage. The second portion is the gradual adsorption stage, in which the intraparticle diffusion is rate-controlled. The third portion is the final equilibrium stage, during which the intraparticle diffusion starts to slow down due to extremely low solute concentrations in the solution.

In general, the kinetics of methyl orange and Congo red adsorption onto all adsorbents were best described by the pseudo-second-order model based on the correlation coefficient values for all three equations.

\section{Adsorption thermodynamics}

The adsorption thermodynamic parameter, i.e., Gibbs free energy change for adsorption, was calculated using the following equation (Ghaedi et al. 2013a, b):

$\Delta G^{\circ}=-R T \ln K_{c}$

where $R$ is the universal gas constant $\left(8.314 \mathrm{~J} \mathrm{~mol}^{-1} \mathrm{~K}^{-1}\right)$, $T$ is the temperature $(\mathrm{K})$, and $K_{c}$ is the equilibrium constant. Values of $K_{c}$ may be calculated from the relation $\ln q_{\mathrm{e}} / C_{\mathrm{e}}$ versus $q_{\mathrm{e}}$ at different temperatures and extrapolated to zero. The calculated thermodynamic parameters are listed in Table 3 . The negative $\Delta G^{\circ}$ values confirm the spontaneous nature and feasibility of the adsorption process. The
Table 3 Thermodynamic parameters for the adsorption of dye onto SiC-NP-AC and AC

\begin{tabular}{|c|c|c|c|c|c|c|}
\hline \multirow[t]{2}{*}{ Adsorbate } & \multirow[t]{2}{*}{ Parameter } & \multicolumn{5}{|c|}{ Temperature (K) } \\
\hline & & 293.15 & 303.15 & 313.15 & 323.15 & 333.15 \\
\hline \multicolumn{7}{|l|}{$\mathrm{SiC}-\mathrm{AC}$} \\
\hline \multirow[t]{4}{*}{ Congo red } & $\mathrm{K}^{\circ}$ & 2.8183 & 2.1576 & 1.9958 & 1.4516 & 1.3348 \\
\hline & $\Delta \mathrm{G}^{\circ}(\mathrm{kJ} / \mathrm{mol})$ & -2.5240 & -1.9372 & -1.7983 & -1.0007 & -0.7995 \\
\hline & $\Delta \mathrm{H}^{\circ}(\mathrm{kJ} / \mathrm{mol})$ & -15.338 & & & & \\
\hline & $\Delta \mathrm{S}^{\circ}(\mathrm{J} / \mathrm{mol})$ & -43.850 & & & & \\
\hline \multirow[t]{4}{*}{ Methyl orange } & $\mathrm{K}^{\circ}$ & 2.3546 & 1.8694 & 1.5833 & 1.0068 & \\
\hline & $\Delta \mathrm{G}^{\circ}(\mathrm{kJ} / \mathrm{mol})$ & -2086.09 & -1576.07 & -1195.79 & -18.260 & \\
\hline & $\Delta \mathrm{H}^{\circ}(\mathrm{kJ} / \mathrm{mol})$ & -21497.0 & & & & \\
\hline & $\Delta \mathrm{S}^{\circ}(\mathrm{J} / \mathrm{mol})$ & -65.8380 & & & & \\
\hline \multicolumn{7}{|l|}{ Activated carbon } \\
\hline \multirow[t]{4}{*}{ Congo red } & $\mathrm{K}^{\circ}$ & 4.0276 & 2.5561 & 1.5075 & 1.1272 & 0.6733 \\
\hline & $\Delta \mathrm{G}^{\circ}(\mathrm{kJ} / \mathrm{mol})$ & -3393.8 & -2364.26 & -1068.15 & -321.56 & -26.57 \\
\hline & $\Delta \mathrm{H}^{\circ}(\mathrm{kJ} / \mathrm{mol})$ & -28907 & & & & \\
\hline & $\Delta \mathrm{S}^{\circ}(\mathrm{J} / \mathrm{mol})$ & -87.77 & & & & \\
\hline \multirow[t]{4}{*}{ Methyl orange } & $\mathrm{K}^{\circ}$ & 3.0650 & 3.0650 & 3.0650 & 3.0650 & 3.0650 \\
\hline & $\Delta \mathrm{G}^{\circ}(\mathrm{kJ} / \mathrm{mol})$ & -2728.47 & -2728.47 & -2728.47 & -2728.47 & -2728.47 \\
\hline & $\Delta \mathrm{H}^{\circ}(\mathrm{kJ} / \mathrm{mol})$ & -26065 & & & & \\
\hline & $\Delta \mathrm{S}^{\circ}(\mathrm{J} / \mathrm{mol})$ & -80.70 & & & & \\
\hline
\end{tabular}


standard entropy and enthalpy change for adsorption can be calculated from the slope and intercept of $\ln K^{\circ}$ versus $1 / T$ by using the Van't Hoff equation.

$\ln K^{\circ}=\left(\frac{\Delta S^{\circ}}{R}\right)-\left(\frac{\Delta H^{\circ}}{R T}\right)$

The negative value of $\Delta H^{\circ}$ reflects endothermic adsorption of dyes on to adsorbents, while the negative value of $\left(\Delta \mathrm{S}^{\circ}\right)$ indicates a decrease in the degree of freedom (or disorder) of the adsorbed species.

\section{Conclusion}

The removal of methyl orange and Congo red from aqueous solution was studied using activated carbon and SiCNP-AC as adsorbents. A higher adsorption capacity was found for SiCNP-AC. Equilibrium adsorption data were best described by the Langmuir isotherm model. The kinetic data were better fitted using the pseudo-second-order model compared to the pseudo-first-order model, intraparticle diffusion, and the Elovich model. This paper demonstrates that SiCNP-AC can be regarded as a novel adsorbent in terms of low equilibrium time and high adsorption capacity. The kinetics of the adsorption processes can be successfully fitted to the pseudo-second-order model. The calculated thermodynamic adsorption parameters showed that adsorptions of both dyes onto activated carbon and SiCNP were spontaneous and exothermic under the experimental conditions.

Acknowledgments The authors are grateful for the financial support (Grant number: 32/1012) from the Research Councils of Ilam University.

\section{References}

Alishavandi Z, Mosallanejad N, Shabani R (2013) Silvernano particle loaded on activated carbon as novel adsorbent for the removal of acid yellow 199 dye. J Chem Health Risks (JCHR) 3:53-68

Ameta SC, Punjabi PB, Vardia J, Madhwani S, Chaudhary S (2006) Use of bromophenol red-EDTA system for generation of electricity in a photogalvanic cell. J Power Sources 159:747-751

Aysu T, Kucuk MM (2015) Removal of crystal violet and methylene blue from aqueous solutions by activated carbon prepared from Ferula orientalis. Int J Environ Sci Technol 12:2273-2284

Chatterjee S, Chatterjee S, Chatterjee BP, Guha AK (2007) Adsorptive removal of congo red, a carcinogenic textile dye by chitosan hydrobeads: Binding mechanism, equilibrium and kinetics. colloids surf A. Physicochem Eng Aspects 299:146-152

Chen S, Zhang J, Zhang C, Yue Q, Li Y, Li C (2010) Equilibrium and kinetic studies of methyl orange and methyl violet adsorption on activated carbon derived from Phragmites australis. Desalination 252:149-156

Denga S, Niea Y, Dua Z, Huanga Q, Menga P, Wanga B, Huanga J, Yua G (2015) Enhanced adsorption of perfluorooctane sulfonate and perfluorooctanoate by bamboo-derived granular activated carbon. J Hazard Mater 282:150-157

El-Hendawy AA, Alexander AJ, Andrews RJ, Forrest G (2008) Effects of activation schemes on porous, surface and thermal properties of activated carbons prepared from cotton stalks. J Anal Appl Pyrolysis 82:272-278

Freundlich HMF (1906) Over the adsorption in solution. J Phys Chem 57:385-470

Ghaedi M, Ghayedi M, Nasiri Kokhdan S, Sahraei R, Daneshfar A (2013a) Palladium, silver, and zinc oxide nanoparticles loaded on activated carbon as adsorbent for removal of bromophenol red from aqueous solution. J Ind Eng Chem 19:1209-1217

Ghaedi M, Ghayedi M, Nasiri Kokhdan S, Sahraei R, Daneshfar A (2013b) Palladium, silver, and zinc oxide nanoparticles loaded on activated carbon as adsorbent for removal of bromophenol red from aqueous solution. J Ind Eng Chem 19:1209-1217

Ghaedi M, Golestani Nasab A, Khodadoust S, Rajabi M, Azizian S (2014) Application of activated carbon as adsorbents for efficient removal of methylene blue: kinetics and equilibrium study. Ind Eng Chem 20:2317-2324

Ghazi Mokri HS, Modirshahla N, Behnajady MA, Vahid B (2015) Adsorption of C.I. acid red 97 dye from aqueous solution onto walnut shell: kinetics, thermodynamics parameters, isotherms. Int J Environ Sci Technol 12:41401-41408

Giles CH, Smith D (1973) A general treatment and classification of the solute adsorption isotherm I. Theor J Colloid Interface Sci 47:755-765

Gueu S, Yao B, Adouby K, Ado G (2007) Kinetics and thermodynamics study of lead adsorption on to activated carbons from coconut and seed hull of the palm tree. Int J Environ Sci Tech 4:11-17

Hu C, Zhou J, He S, Luo Z, Cen K (2009) Effect of chemical activation of an activated carbon using zinc chloride on elemental mercury adsorption. Fuel Process Technol 90:812-817

Hwang HJ, Nishihara A (1998) Perovskite-type $\mathrm{BaTiO}_{3}$ ceramics containing particulate SiC: part II Microstructure and mechanical properties. J Mater Sci 33:549-558

Kannan N, Sundaram MM (2001) Kinetics and mechanism of removal of methylene blue by adsorption on various carbons-a comparative study. Dyes Pigments 51:25-40

Khaled A, Nemr AE, El-Sikaily A, Abdelwahab O (2009) Spent tea leaves: a new non conventional and low cost adsorbent for removal of basic dye from aqueous solutions. Desalination 238:210-232

Kim M, Kim J (2014) Development of high power and energy density microsphere silicon carbide- $\mathrm{MnO} 2$ nanoneedles and thermally oxidized activated carbon asymmetric electrochemical supercapacitors. Phys Chem Chem Phys 16(23):11323-11336

Langmuir I (1916) The constitution and fundamental properties of solids and liquids. part i. solids. J Am Chem Soc 38:2221-2295

Lavrenko VA, Desmaison-Brut M, Panasyuka AD, Dasmaison J (1999) Mechanisms of deformation of silicon nitride and silicon carbide at high temperatures. J Eur Ceram Soc 18:2339

Li W, Peng J, Zhang L, Xia H, Li N, Yang K, Zhu X (2008) Investigations on carbonization processes of plain tobacco stems and $\mathrm{H}_{3} \mathrm{PO}_{4}$-impregnated tobacco stems used for the preparation of activated carbons with $\mathrm{H}_{3} \mathrm{PO}_{4}$ activation. Ind Crop Prod 28:73-80

Lopez-Ramon MV, Stoeckli F, Moreno-Castilla C, Maring-Carrasco F (1999) On the characterization of acidic and basic surface sites on carbons by various techniques. Carbon 37:1215-1221

Lu C, Chung YL, Chang KF (2006) Adsorption thermodynamic and kinetic studies of trihalomethanes on multiwalled carbon nanotubes. J Hazard Mater 138:304-310

Manoj Kumar Reddy P, Krushnamurty K, Mahammadunnisa SK, Dayamani A, Subrahmanyam CH (2015) Preparation of 
activated carbons from bio-waste: effect of surface functional groups on methylene blue adsorption. Int J Environ Sci Technol 12(4):1363-1372

Mezohegyi G, Vander Zee FP, Font J, Fortuny A, Fabregat A (2012) Towards advanced aqueous dye removal processes: a short review on the versatile role of activated carbon. J Environ manage 102:148-164

Neill CO, Hawkes FR, Hawkes DL, Lourenco N, Pinheiro HM, Delee W (1999) Colour in textile effluents-sources, measurement, discharge consents and simulation: a review. J Chem Technol Biotechnol 74:1009-1018

Pezzotti G, Sakai M (1994) Effect of silicon carbide "nano dispersion" on the mechanical properties of silicon nitride. J Am Ceram Soc 77:3039-3041

Pham-Huu C, Estournes C, Heinrich B, Ledoux MJ (1998) High temperature $\mathrm{H}_{2} \mathrm{~S}$ removal over high specific surface area [beta]$\mathrm{SiC}$ supported iron oxide sorbent part 1 preparation and characterization. J Chem Soc Faraday Trans 18:435-442

Poinern GEJ, Senanayake G, Shah N, Thi-Le X, Parkinson GM, Fawcett D (2011) Adsorption of the aurocyanide, $\mathrm{Au}(\mathrm{CN})_{2}-$ complex on granular activated carbons derived from macadamia nut shells-a preliminary study. Miner Eng 24:1694-1702

Pourreza N, Naghdi T (2014) Silicon carbide nanoparticles as an adsorbent for solid phase extraction of lead and determination by flame atomic absorption spectrometry. J Ind Eng Chem 20:3502-3506

Rengaraj S, Kim Y, Joo CK, Yi J (2004) Removal of copper from aqueous solution by aminated and protonated mesoporous aluminas: kinetics and equilibrium. J Colloid Interface Sci 273:14-21

Rudnik E (2013) Incorporation of ceramic particles into nickel and cobalt electroless deposits. Adv Mater Sci Appl 2:1-8

Strachowski P, Bystrzejewski M (2015) Comparative studies of sorption of phenolic compounds onto carbon-encapsulated iron nanoparticles, carbon nanotubes and activated carbon. Colloids Surf A 467:113-123

Subramonian W, Wu TY (2014) Effect of enhancers and inhibitors on photocatalytic sunlight treatment of methylene blue. Water Air Soil Pollut 225(4):1-15. doi:10.1007/s11270-014-1922-0

Temkin MJ, Pyzhev V (1940) Recent modifications to Langmuir isotherms. Acta Physiochim RSS 12:217-222

Timura S, Cem Kantarlib I, Onenca S, Yanika J (2010) Characterization and application of activated carbon produced from oak cups pulp. J Anal Appl Pyrolysis 89:129-136
Tutem E, Apak R, Unal CF (1998) Adsorptive removal of chlorophenols from water by bituminous shale. Water Res 32:2315-2324

Ubago-Perez R, Carrasco-Marin F, Fairen-Jimenez D, MorenoCastilla C (2006) Granular and monolithic activated carbons from $\mathrm{KOH}$-activation of olive stones. Micropor Mesopor Mater 92:64-70

Vargas AMM, Garcia CA, Reis EM, Lenzi E, Costa WF, Almeida VC (2010) $\mathrm{NaOH}$ activated carbon from flamboyant (Delonix regia) pods: optimization of preparation conditions using central composite rotatable design. Chem Eng J 162:43-50

Vargas AMM, Cazetta AL, Kunita MH, Silva TL, Almeida VC (2011) Adsorption of methylene blue on activated carbon produced from flamboyant pods (delonix regia): study of adsorption isotherms and kinetic models. Chem Eng J 168:722-730

Wang Z (2015) Efficient adsorption of dibutyl phthalate from aqueous solution by activated carbon developed from phoenix leaves. Int J Environ Sci Technol 12:1923-1932

Wu FC, Tseng RL, Juang RS (2005a) Preparation of highly microporous carbons from fir wood by $\mathrm{KOH}$ activation for adsorption of dyes and phenols from water. Sep Purif Technol 47:10-19

Wu FC, Tseng RL, Juang RS (2005b) Comparisons of porous and adsorption properties of carbons activated by steam and $\mathrm{KOH}$. J Colloid Interface Sci 283:49-56

Wu TY, Mohammad AW, Lim SL, Lim PN, Hay JXW (2013) Recent advances in the reuse of wastewaters for promoting sustainable development. In: Sharma SK, Sanghi R (eds) Wastewater reuse and management. Springer, Netherlands, p 47. doi:10.1007/97894-007-4942-9_3

Zabaniotou A, Stavropoulos G, Skoulou V (2008) Activated carbon from olive kernels in a two-stage process: industrial improvement. Bioresour Technol 99:320-326

Zakaria ZA, Suratman M, Mohammed N, Ahmad WA (2009) Removal aqueous solution by untreated rubber wood of methylene blue from waste stream by fly sawdust. Desalination 244:109-121

Zolfaghari G, Esmaili-Sari A, Anbia M, Younesi H, Ghasemian MB (2013) A zinc oxide-coated nanoporous carbon adsorbent for lead removal from water: optimization, equilibrium modeling, and kinetics studies. Int J Environ Sci Technol 10(2):325-340 